\section{THE MIRROR OF JAPAN, AND ITS MAGIC QUALITY}

$\mathrm{THE}$ lecturer commenced by referring to the vast differences between the Chinese and the Japanese nations, of which the English people, as a rule, do not seem to be aware. He instanced various points of contrast; one of the most important being the intensely oriental secluded character of the private life of the Chinese on the one hand, and the Japanese dwelling in houses unfurnished and left wide open to the public gaze on the other. But why, he asked, in this comparative absence of nearly all that we should call furniture, does one article pertaining to the ladies' toilet--the bronze mirror with its standhold so prominent a position?

This mirror of the Far East is usually circular, from three to twelve inches in diameter, made of bronze, and with a bronze handle covered with bamboo. The reflecting face is generally more or less convex, polished with a mercury amalgam; the back is gracefully ornamented with a wellexecuted raised design representing birds, flowers, dragons, a geometrical pattern, or some scene in Japanese mythical history." Occasionally there are also one or more Chinese characters (signifying long life, happiness, or some similar idea) of polished metal, in bold relief. 'The general appearance of the back of the mirror, therefore, is something like that seen in the accompanying figure.

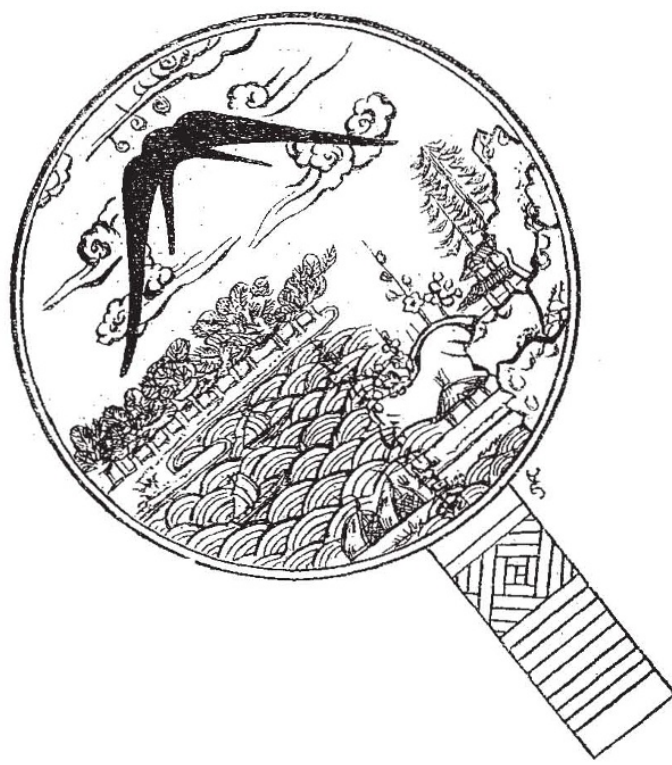

It might at first sight be surmised that the elaborate head-dresses of the ladies in Japan, combined with the painting of their faces, furnished an explanation of the prominence given to the metal mirror. But that this is not the case is easily seen from the fact that it is in the Imperial Palace, where the court ladies, still preserving the simple fashion of ancient days, merely comb back their long black tresses, and so have least need of a looking-glass, that the Japanese mirror receives the highest respect. A foreigner meets the mirror in the temples, in the hands of the street-conjuror, in pictures of the infernal regions, and in the regalia of the Japanese sovereigns, and for some time after his arrival in Japan, feels as an Oriental ignorant of biblical history might when unable to understand the constant repetition of the cross in Roman Catholic countries. But at length he hears that the mirror is part of the Japanese religion and mixed up with the "divine right of kings"; that it is the

${ }^{1}$ The Friday evening discourse at the Royal Institution, January ${ }_{24}$, by Prof. W. E. Ayrton. most precious of the possessions of a Japanese woman, and constitutes the most important part of the trousseav of a bride, and "the two Great Divine Palaces" at Isé, in which was deposited the first made mirror, have in the eyes of the Japanese the same importance as has the Holy Sepulchre for the Greeks and Armenians, and Mecca for the Mohammedans.

And to realise the reason of this, the stranger must learn that there is a famous ancient myth in Japan, which was recounted by the lecturer, detailing how the sungoddess in a rage shut herself up in a rocky cave, and how the other gods to dispel the darkness thus caused, used various artifices to entice her forth, the most successful ruse being the manufacture of the first historical mirror, in which, seeing her face, she was drawn forth by her curiosity and jealousy. He will also learn how in the supposed creation of the Japanese Empire, the sun-goddess is reputed to have handed this mirror (with the two other "god's treasures," which, together with a mirror, at present constitute the regalia of the Emperor). to her grandson with these words, "Look upon this mirror as my spirit, keep it in the same house and on the same floor with yourself, and worship it as if you were worshipping my actual presence."

After describing many interesting points in connection with this strange mirror-worship of the Japanese, as seen in the palace and in the cottage, the lecturer went on to say that to the majority of those present the investigation of the so-called magic properties of the Japanese mirror would probably prove of yet more interest.

This magic property, which is possessed by a few rare specimens coming from the East, is as follows: If the polished surface is looked at directly, it acts like an ordinary mirror reflecting the objects in front of it, but giving, of course, no indication whatever of the raised patterns on the back; if, however, a bright light be re: flected by the smooth face of the mirror on to a screen, there is seen on this screen an image formed of bright lines on a dark ground more or less perfectly representing the pattern on the back of the mirror, which is altogether hidden from the light.

When this appearance is seen for the first time it is perfectly startling even to an educated mind, and if the source of light is sufficiently bright, as for instance a tropical sun, it is difficult for the observer to divest himself of the idea that the screen is not perforated with cuts, corresponding with the pattern on the back of the mirror, and illuminated from behind.

This strange phenomenon was known to both Sir David Brewster and Sir Charles Wheatstone, both of whom were of opinion that it was produced by trickery on the part of the maker. Sir David Brewster, for example, says in the Philosophical Magazine for December, 1832 "Like all other conjurors, the artist has tried to make the observer deceive bimself. The stamped figures on the back (of the mirror) are used for this purpose. The spectrum in the luminous area is not an image of the figures on the back. The figures are a copy of the picture which the artist has drawn on the face of the mirror, and so concealed by polishing that it is invisible in the ordinary lights, and can be brought out only in the sun's rays."

Prof. Ayrton then related bow he bad been quite unable to find for sale in any of the shops of Japan one of these magic mirrors, which was supposed in Europe to be a standard Japanese trick, and he explained how he had at length ascertained that with regard to this socalled magic mirror, the Japanese were the people who knew least about the subject.

But these magic mirrors were known to the Chinese from the earliest times, and one of their writers spoke about them in the ninth century of the Christian era. They call them theou-kooang-kien, which means literally, "mirrors that let the light pass through them," this name, 
of course arising from a popular error on the subject. The Roman writer Aulus Gellius, who lived seventeen centuries ago, referred to mirrors that sometimes reflected their backs and sometimes did not. From the great antiquity of these Chinese magic mirrors, the German writer Herr Sterne has concluded that it is probable that the mirrors with secret signs and figures of imps on the back, which formed a portion of the stock-in-trade of the witches of the middle ages, were of Eastern manufacture. The Italian historian Muratori gives an account of the magic mirror found under the pillow of the Bishop of Verona, who was afterwards condemned to death by Martin Della Scala, as well as of the one discovered in the house of Colla da Rienzi, and on the back of which was the word "Fiòrone:" But of these magic mirrors, which have played so important a part, not only in the priestcraft of China, but also in the oracles of the Greeks and Etruscans, and in the witchcraft of the middle ages, inquiry has shown that Japanese literature makes absolutely no mention.

Is it, then, that such mirrors cannot be found in Japan? Undoubtedly they cannot be bought on inquiry at the shops, but Prof. Ayrton's investigations have shown that if a careful examination with properly arranged light be made of a large number of the ordinary Japanese bronze mirrors; a few, perhaps 2 or 3 per cent., will be found showing the magic property clearly.

The lecturer then referred to the extracts he bad made from a large portion of that which had been written in various languages regarding the explanation of the phenomenon. He mentioned that the earliest explanation was given by a Chinaman, Ou-tseu-hing, who lived between 1260 and 1341 , and who also had the impression that the magic property of the mirror was produced by an artifice; for he wrote: "When we turn one of the mirrors with its face to the sun, and allow it to throw a reflection on a wall close by, we see the ornaments or the characters which exist in relief on the back, clearly. Now the cause of this phenomenon arises from the employment of two kinds of copper of unequal density. If on the back of the mirror a dragon has been produced while casting it in the mould, then an exactly similar dragon is deeply engraved on the face of the disk. Afterwards the deep chisel cuts are filled up with denser copper, which is incorporated with the body of the mirror which ought to be of finer copper, by submitting the whole to the action of fire; then the face is planed and prepared, and a thin layer of lead or of tin spread over it. ${ }^{2}$

"When a beam of sunlight is allowed to fall on a polished mirror prepared in this way, and the image is reflected on a wall, bright and dark tints are distinctly seen, the former produced by the purer copper, and the latter by the parts in which the denser copper is inlaid."

Ou-tseu-hing adds that he has seen a mirror of this kind broken into pieces, and that he has thus ascertained for himself the truth of this explanation.

In a paper communicated some years ago to the French Academy of Sciences, the well-known French writer on China, M. Stanislaus Julien, says: "Many famous philosophers have for a long time, but without success, endeavoured to find out the true cause of the phenomenon which has caused certain metallic mirrors constructed in China to have acquired the name of magic mirrors. Even in the country itself where they are made, no European has up to the present time been able to obtain either from the manufacturers, or from men of letters, the information which is so full of interest to us, because the former keep it a secret when by chance they possess it, and the latter generally ignore the subject altogether. I had found many times in Chinese books details regarding this kind of mirrors, but it was not of a nature to

I This probably refers to the mercury-amalgam which is used in polishing, and which Ou-tseu-hing mistook for lead or tin. satisfy the very proper curiosity of the philosopher, because sometimes the author gave on his own responsibility, an explanation that he had guessed at, and sometimes he confessed in good faith that this curious property is the result of an artifice in the manufacture, the monopoly of which certain skilled workmen reserve to themselves. One can easily understand this prudent reticence when we remember that the rare mirrors which show this phenomenon sell from ten to twenty times as dear as the rest."

The prevalent idea has been that the phenomenon of the magic mirror was caused by a difference of density in the various parts of the surface, either produced intentionally or accidentally; and this, the lecturer explained, arose from two causes, first, from the common belief that the patterns on Japanese and Chinese mirrors were, like those on ordinary coins, produced by stamping; the other, because the distinguished European philosophers who had examined into the question had investigated with considerable success, experimentally, how such mirrors might be made, but they had not, the lecturer thought, directed their attention to the examination of the question-How was the phenomenon in these rare eastern mirrors actually produced?-obviously a very different question.

Prof. Ayrton mentioned that he and Prof, Perry were led to take up the investigation from a very remarkable fact pointed out by Prof. Atkinson, of Japan, viz., that a scratch with a blunt iron nail on the back of one of these magic mirrors, although it produced no mark on the face of the mirror which could be seen by direct vision, nevertheless became visible as a bright line on the screen when a beam of sunlight was reflected from the polishes? face of the mirror. The lecturer mentioned that aftes trying several experiments with polarised light, \&c., Prof. Perry and himself availed themselves of a very simple method of investigation, but one which had apparently not suggested itself to previous observers. On one occasion, when some of their students were using lenses to endeavour to make the exhibition of the phenomenon more striking, it occurred to them that the employment of beams of light of different degrees of convergence or divergence would furnish a test for deciding the cause of the whole action. For while, if the phenomenon were due to the molecular differences in the surface-the commonly received opinion-the effect would be practically independent of the amount of convergence of the beam of light; on the other hand, if it by any chance were due to portions of the reflecting surface being less convex than the remainder, a complex inversion of the phenomenon might be expected to occur, if the experiment, instead of being tried in ordinary sunlight, were made under certain conditions in a converging beam-that is, the thicker portions of the mirror might be expected to appear darker instead of lighter than the remainder.

[Experiments were then shown of the image cast on the screen: ( $I$ ) when a divergent beam of light fell on the mirror, (2) when the beam was parallel, (3) when the beam was convergent; and it was seen (I) the pattern appeared as bright on a dark ground, (2) the pattern was invisible, (3) the pattern appeared as dark on a light ground.]

Again, by allowing a parallel beam of light to fall on it, and interposing a double convex lens between the mirror and the screen, we can make the image show the pattern either as a bright on a dark ground, or as dark on a bright ground, or not at all, merely by causing the screen to be: ist, nearer the lens than the conjugate focus of the mirror; 2nd, farther than the conjugate focus ; 3 rd, at the conjugate focus. [This experiment was here shown.] Now it can easily be proved by simple geometrical optics that each of these effects would be produced if the thicker parts of the mirror were a little less convex than the remainder. [This was explained by various geometrical 
diagrams.] And lastly, if the phenomenon was, as the previous experiment would lead us to conclude, due not to unequal reflecting power of the different portions of the surface of the mirror, but to minute inequalities on the surface, in consequence of which there is more scattering power of the rays of light falling on one portion than on another, then, since rays of light making very small angles with one another do not separate perceptibly until they have gane some distance, it follows that if the screen be held very near to the mirror, the apparent reflection of the back, the magical property, in fact, ought to become invisible. And this also, it was shown, was exactly what happened when the screen was made almost to touch the polished surface.

The lecturer then proceeded to explain why a divergent beam emitted by a bright luminous point at some fifteen feet distance from the mirror gave the best effects.

We have therefore strong reasons for favouring the "in equality of curvature" theory. In order, however, to make the explanation quite certain, the lecturer said he had made a small concavity and a small convexity on the face of one of the mirrors, by hammering with a blunt tool, carefully protected with a soft cushion to avoid scratching the polished surface, and he showed by experiment that the concavity reflected a bright image and the convexity a dark one, when the pattern on the back ap. peared bright, but when the light was so arranged that the pattern appeared as dark on a bright ground, it was the convexity which appeared as the bright spot and the concavity as the dark one.

Guided by all that precedes, we are led to the undoubted conclusion that the whole action of the magic mirror arises from the thicker portions being flatter than the remaining convex surface, and even being sometimes actually concave. But, in spite of this irresistible conclusion forced on us by the experiments previously mentioned, it must be admitted that it seems extraordinary how such small inequalities in the surface of the mirror, so small in fact that the eye quite fails to detect them, can, even with a proper arrangement of the light, produce on the screen an image of the pattern on the back as sharp and clear as is seen with a good specimen of the magic mirror.

The next question arises, why is there this difference in the curvature of the different portions of the surface? 'The experience that Prof. Ayrton had gained from an examination of a large number of Japanese mirrors supplied, in part at any rate, the answer to the question. No thick mirror reflects the pattern on the back, not one of the many beautiful mirrors exhibited at the National Exhibition of Japan in 1877 , and which the lecturer was so fortunate as to be able to experiment with in a darkened room with a bright luminous point at some twelve feet distance, showed the phenomenon in the slightest degree; some good old mirrors in the museum of the Imperial College of Engineering, and which belonged to the family of the late Emperor, the Shogun, of Japan, failed to reflect any trace of a design, and some old round mirrors without handles, which he had also tried, were (with the exception of one which was immensely prized, and brought to him wrapped in fire distinct silk cases, and the heirloom of the family of a nobleman) equally unsuccessful.

Again, it is not that the pattern is less clearly executed on the backs of these choice mirrors, since the better the mirror the finer and bolder is the pattern, but what is especially noticeable is that every one of these mirrors is, as a whole, far thicker than an ordinary Japanese mirror, and its surface is much less convex.

This naturally led him to inquire how are Japanese mirrors made convex? Are they cast so, or do they acquire this shape from some subsequent process? His search through all the literature at his disposalEuropean, Japanese, Chinese-on the subject of mirrors failed to elicit the slightest hint; he was therefore compelled to perform the somewhat difficult task of obtaining information from the Japanese workmen themselves. Eventually he ascertained that while practically all Japanese mirrors were convex, the surface of each half of the mould was flat, and that the curvature was given to the mirror after casting in the following way: the rough mirror is first scraped approximately smooth with a handscraping tool, and as this would remove any small amount of convexity had such been imparted to it in casting, it is useless to make the mould slightly convex. If, however, a convex or concave mirror of small radius is required, then the surface of the mould is made concave or convex. On the other hand, to produce the small amount of convexity which is possessed by ordinary Japanese mirrors the following method is employed, if the mirror is thin, and it is with thin mirrors we have especially to deal, since it is only in these mirrors that the apparent reflection of the back is observed. The mirror is placed face uppermost on a wooden board, and then scraped or rather scratched with a rounded iron rod about a third of an inch in diameter, and a foot long, called a megebo, "distorting rod," so that a series of small parallel scratches is produced, which causes the face of the mirror to become convex in the direction at right angles to the scratches, but to remain straight parallel to the scratches, in fact it becomes very slightly cylindrical, the axis of the cylinder being parallel to the scratches. This effect is very clearly seen by applying a straight-edge in different ways to the face of an unpolished mirror which has received a single set of scratches only. A series of scratches is next made with the megebo in a direction of right angles to the former, a third set intermediate between the two former, and so on, the mirror each time becoming slightly cylindrical, the axis of the cylinder in each case being parallel to the line of scratches, so that eventually the mirror becomes generally convex. Some workmen prefer to make the scratches with the megebo in the form of small spirals, others in the form of large spirals, but the general principle of the method employed with their mirrors appears to be always the same--the face of the mirror is scratched with a blunted piece of iron, and becomes slightly convex, the back, therefore, becoming concave.

[Mirrors were here exhibited, one with its surface flat, although somewhat rough, just as it came from the mould after casting; a second that had received one set of parallel scratches with the megebo, and which by means of a straight edge was shown to be slightly cylindrical; and a third on the face of which the operation of scratching had been completed, and which was therefore slightly convex.]

After the operation with the "distorting-rod" the mirror is very slightly scraped with a hand-scraping tool. to remove the scratches, and to cause the face to present a smooth surface for the subsequent polishing.

In the case of thick mirrors the convexity is first made by cutting with a knife, and the distorting-rod applied afterwards. But in connection with this cutting process of thick mirrors, there is one very interesting point. If the maker finds, on applying from time to time the face of the mirror to a hard clay concave pattern, and turning it round under a little pressure, that a portion of the surface has not been in contact with the pattern, in other words, that he has cut away this portion too much, then he rubs this spot round and round with the megebo until he has restored the required degree of convexity. Here again, then, scratching on the surface produces convexity,

Now, why does the scraping of the "distorting rod" across the face of the mirror leave it convex? During the operation it is visibly concave. The metal must receive, then, a kind of "buckle," and spring back again so as to become convex when the pressure of the rod is removed. It might in such a case reasonably be expected that the thicker parts of the mirror would yieid less to 
the pressure of the rod than the thinner, and so would be made less convex, or even they might not spring back, on the withdrawal of the rod and so remain actually concave. Again, since we find that scraping the face of the mirror is the way in which it is made convex, and the back therefore concave, we might conclude that a deep scratch on the back would made the back convex and the face slightly concave. Such a concavity would, as we have proved, explain the phenomenon of the bright line appearing in the reflection of sunlight on the screen, which was observed by Prof. Atkinson to correspond with the scratch on the back.

After the scratches produced by the megebo are removed the mirror is polished with whetstones and then with charcoal. The face now becomes fairly smooth, but it still generally contains some few cavities; these the maker fills up from a stock of copper balls of various sizes which he has at hand. (It was probably the presence of these bits of copper that led Ou-tseu-hing to believe that the explanation of the cause of the magic mirrors was the inlaying of different metals.) The face of the mirror is finally rubbed over with a mercury amalgam containing 50 per cent of tin, by means of a small straw brush or the hand.

The lecturer then referred to the various metal mixtures employed by the Japanese in making their mirrors, the best being composed of 75 per cent. of copper, 23 of tin, and 2 per cent. of a natural sulphide of lead and antimony.

Although the Japanese have paid no attention to the magic mirror, which has created such interest in Europe, they have, in connection with their priestcraft, employed mirrors on the surface of which, if looked at obliquely, could be seen the faces of saints, but which were not in any way connected with the pattern on the back of the mirror. [Photographs of such mirrors were projected on to the screen.] The lecturer also exhibited two mirrors of this kind which he had had made in consequence of the belief expressed by one of the Japanese mirror-makers that the phenomenon of the so-called magic mirrors was produced by chemical action on the surface. But the result of the experiment had been that if the face of a mirror which had been chemically acted on was polished until every trace of the marks disappeared for direct or oblique vision, then they also disappeared in the image produced by reflecting a beam of light on to a screen, and consequently that it did not seem possible, as far as his experiments had gone, to produce, by means of chemical action on the surface, a mirror fulfilling all the conditions of the magic mirror.

He concluded by saying: "It appears, then, contrary to what is commonly believed, that the magic of the Eastern mirror results from no subtle trick on the part of the maker, from no inlaying of other metals or hardening of portions by stamping, but merely arises from the natural property possessed by certain thin bronze of buckling under a bending stress, so as to remain strained in the opposite directions after the stress is removed. And this stress is applied partly by the distorting rod, and partly by the subsequent polishing, which, in an exactly similar way, tends to make the thinner parts more convex than the thicker."

\section{GEOGRAPHICAL NOTES}

THE April number of Petermann's Mittheilungen contains a paper of considerable geographical and geological value by Dr. Edmund Naumann, on the Plain of Yedo, Japan; it is accompanied by several illustrations and a fine map. Lieut. Onatzewich's account of his cruise in the clipper $W$ ssadnik to the north of Behring Strait in 1876 , is well timed in connection with the Vega's sojourn in that region. Dr. von Scherzer contributes an interesting paper on anthropometry, and Capt. Johannesen describes the voyage of the Len from the mouth of the
River Lena to Jakutsk. The monthly summary contains, as usual, many interesting items.

THE February number of the Bulletin of the Paris Society gives M. Savorgnan de Brazza's paper on his Ogowé expedition, the results of which we have already stated. A valuable and detailed notice of Dalmatia is contributed by M. de Sainte-Marie, and the number contains the recent correspondence of Dr. Crevaux from Guiana, referred to last week. The Nouvelles are continued.

As we stated last week, though M. Soleillet has got so far on his journey to Timbuktu, it must not be forgotten that some fifteen years ago Lieut. Mage and Dr. Quintin reached the same place, and that after being detained as prisoners for eighteen months by the present Sultan Ahmadu, they were refused permission to embark on the Niger, and compelled to return to the coast re infectâ. Indeed, just as we go to press we learn that a telegram. sent to the French Société de Géographie announces that the progress of M. Soleillet has been cut short. He was stopped by Ahmadu, the Emperor of Segou under the pretence that the roads are insecure in the north of his government. M. Soleillet has returned to St. Louis.

WiTH reference to our note last week (p. 516) on the Conference in connection with the Inter-oceanic Canal, M. Maunoir, Secretary of the Paris Geographical Society, writes us that the Conference is to be held on May io under the auspices of that Society and not of the Society of Commercial Geography. The Congress, M. Maunoir writes, will not have any particular project in view, but will give an impartial hearing to the various projects brought before it. The various solutions of the questions proposed will be propounded by their authors, and, if deemed advisable, the Congress may in the end give its approval of one or other of the projects.

THE April number of the Church Missionary Intelligencer states that letters have been received from the missionary reinforcements who are travelling up the Nile to join the Nyanza expedition. They only reached Lada opposite Gondokoro, on October Io; after three weeks stay at that Egyptian station they reached Regiaf on November 7. The cause of delay, we are told, has been that the Nile has been unusually high, and the immense quantity of water loosened great masses of reeds and papyrus which formed floating islands and blocked up the river, besides which, owing to a deficiency of fuel between Khartoum and Lado, they remained fast bound during the whole month of September some distance south of Sobat, and the missionaries saw no living beings (besides the men on board) but "pelicans, fishes, and a whiteheaded eagle or two."

ANNEXED to the recently issued report of Her Majesty's Consul on the newly-opened port of Wênchow, is a very interesting map of the three Chinese provinces of Chekiang, Fukien, and Kiangsi, showing the means of communication by land and water between the principal cities and districts. The object of the map is more especially to point out the position of Wênchow as regards some of the most important districts in these provinces, the names of which with their products are given.

GARIBALDI has snubbed the Italian New Guinea expedition, so that it may now be regarded as nipped in the bud.

THE collection of funds instituted by the Dutch Central Committee for Arctic Exploration for the renewed outfitting of the Willem Barentz, which vessel is shortly to start on another expedition of some eighteen months' duration, is progressing so favourably that it may be reasonably expected that the 50,000 florins which are required for the expedition will soon be completely subscribed. 